International Journal of Linguistics, Literature and Translation

ISSN: 2617-0299 (Online); ISSN: 2708-0099 (Print)

DOI: $10.32996 /$ ijllt

Journal Homepage: www.al-kindipublisher.com/index.php/ijltt

IJLLT

\title{
On Subtitle Translation of Chinese Costume Drama, The Longest Day in Chang'an
}

\author{
YU Yanling ${ }^{1}$ and XIA Zhixin ${ }^{2} \square$ \\ 'Professor, School of Foreign Languages, Wuhan University of Technology and Business, China; Mandarin Teacher in CIBL at \\ LSE, China \\ ${ }^{2}$ Master of Wuhan University of Technology, China
}

$\square$ Corresponding Author: XIA Zhixin, E-mail: 2857656199@qq.com

\begin{abstract}
ARTICLE INFORMATION ABSTRACT
Received: 25 September 2021

Accepted: 17 October 2021

Published: 31 October 2021

DOI: $10.32996 /$ ijllt.2021.4.10.25

\section{KEYWORDS}

Costume drama subtitle translation, excellent Chinese culture, functional equivalence,

China's enhanced international influence creates a good environment for spreading its traditional culture overseas. In recent years, Chinese subtitle translation is no longer restricted to translating foreign works into Chinese, with costume drama subtitle translation gaining more and more attention. However, relevant research in China is inadequate, and differences between Chinese and English aggravate this difficulty, which may be solved by studying and analyzing the subtitle translation of The Longest Day in Chang'an under the guidance of Nida's functional equivalence theory from the perspectives of lexical equivalence, syntactic equivalence, and stylistic equivalence, so as to provide the guidance to translators to render a proper translation both in the conveying of information as well as ensuring readers' response.
\end{abstract} The Longest Day in Chang'an, translation methods

\section{Introduction}

In recent years, China's comprehensive national strength and international status have been continuously improved, with cultural confidence enhanced. Vast films and televisions that truly reflect the excellent Chinese traditional culture have emerged one after another and have been translated into multiple languages and disseminated to the world.

The costume drama The Longest Day in Chang'an presents a marvelous culture of the Chinese Tang Dynasty in all aspects. It has been translated into various languages on major overseas platforms, making great contributions to the spread and promotion of China's excellent culture. Among them, the Chinese-English translation of subtitles bounded with profound cultural heritage has aroused heated discussion. "Films and dramas belong to mass communication. As a translation, its fundamental mission is to make the works obtain the conditions for cross-cultural communication through conversion" (Ma Zhengqi, 2012). However, great linguistic and cultural differences exist between China and English. In addition, modern Chinese expression and ancient Chinese expression are also quite different in some aspects, which invisibly increases the difficulty of translation. Therefore, the methods and techniques of studying the Chinese-English translation of subtitles of The Longest Day in Chang'an provide important enlightenment for the study of subtitle translation of Chinese costume translation.

\section{Literature Review}

\subsection{Current Situation of China's Subtitle Translation}

A huge gap exists between China and western society in subtitle translation study. In the late 1950s and early 1960s, the western world began to study subtitle translation. In the 1990s, the research heyday came, during which relevant theories are thriving. In addition, there is a specialized screen translation research organization in Europe, namely ESIST (European Association for studies in screen translation) which has received strong support from the EU. While in China, relevant studies of screen translation started much later. "In China, large-scale screen translation started after the reform and opening up in the 1980s. Despite the significant increase in the number of mass media translation, there are few research fruits in screen translation" (Li Heqing, 2005). What's more, China has not formed any specialized subtitle translation research organization or industry norms. "At present, there are

Copyright: (C) 2021 the Author(s). This article is an open access article distributed under the terms and conditions of the Creative Commons Attribution (CC-BY) 4.0 license (https://creativecommons.org/licenses/by/4.0/). Published by Al-Kindi Centre for Research and Development, London, United Kingdom. 
three kinds of subjects engaged in subtitle translation in China, namely professional subtitle translators, online subtitle groups and individual subtitle translators" (Chen Xi, 2014). However, translators in the market work in their own way, so translation quality is uneven, which is not conducive to the development of subtitle translation. And in the limited subtitle translation studies, most of them are based on the translation of foreign film and television works into Chinese. The author thinks there are two reasons: first, China's researchers do not pay enough attention to the study of popular culture; second, it is closely related to China's international influence. Fortunately, "with the change of film format in the world, the subtitle translation in China has changed from EnglishChinese to Chinese-English translation". It can be seen that there are still many problems in Chinese costume translation and there is a lack of guidance of translation theory and translation methods, which needs to be discussed and solved by the academic community.

\subsection{Functional Equivalence and Subtitle Translation}

Eugene Nida is a world-famous linguist, translator, and translation theorist. His theory of functional equivalence has played an important impact in the global translation circle. In 1964, Nida's Toward A Science of Translating came out. He put forward the concepts of "formal equivalence" and "dynamic equivalence" for the first time. "Dynamic equivalence" means that "in terms of the degree to which the receptors of the message in the receptor language respond to it substantially the same manner as the receptors in the source language (Eugene A Nida, 1964). Later, Nida supplemented dynamic equivalence and proposed "functional equivalence". However, there is essentially not much difference between the two concepts. Functional equivalence can be divided into two levels: the maximal level, that is, "the readers of the translated text should be able to understand and appreciate it in essentially the same manner as the original readers did". The minimal level means is defined as "The readers of a translated text should be able to comprehend it to the point that they can conceive of how the original readers of the text must have understood and appreciated it" (Eugene A Nida, 1982). The maximal level is the ideal translation, which can never be realized, while the translation below the minimal level is not desirable.

Subtitle translation is spatial, instantaneous and needs to cater to public reading habits. In the process of translation, a successful version needs to break the constraints of language and culture, so that the target audience and the original audience can obtain the same understanding and feelings of a film or drama, and make similar responses. Professor Zhang Chunbai said, "film and television translation must be centered on the target language audience and take appropriate care of their language proficiency. This naturally means that the method of screen translation is based on free translation. This is the "functional equivalence" advocated by Nida" (Zhang Chunbai, 1998).

\section{The Embodiment of Functional Equivalence in the Subtitle Translation of the Longest Day in Chang'an}

"As a new field, subtitle translation is very different from traditional literary translation. Its task is to effectively convey the most relevant information to the audience in a specific cultural background according to the intention of the director and the playwright (through pictures and expression style) under the constraints of time and space" (Chen Chunxiang, 2010). The Longest Day in Chang'an abounds with historical and cultural connotations. When subtitles are translated, it is inevitable to encounter translation difficulties due to differences between Chinese and English. The author will study its subtitle translation lexically, syntactically, and stylistically.

\section{i. Lexical equivalence}

Vocabulary plays an important role in the expression of meaning. Plenty of cultural items in the screen translation, like fiction translation, are rather difficult to deal with. As for this drama, some words are rich in cultural meaning. Therefore, literal translation cannot convey the connotative meaning. In this case, the translator should break the shackles of the original text and convey the cultural connotations, including using equivalent words in the target language to narrow the distance between the source language and the target language and make some changes based on the consideration of writing smoothness and logicality.

Example 1: 你可姓李?

\section{Are you the kin of the Emperor?}

Once the original text is literally translated as "Is Li your family name", it is just a simple inquiry about Li Bi's surname, while its connotation is missed. As we all know, the surname "Li" was the royal family name in the Chinese Sui and Tang dynasties. Zhang Xiaojing, the leading character, asked this sentence to know whether Li Bi's huge power was due to his connection with the royal family, rather than his own efforts. This won't cause any comprehensible difficulties for Chinese audiences. However, this kind of cultural difference will confuse the foreign audience who does not know the details of Chinese history. In order to break the barriers of understanding, the translator translates "Li" into "the kin of the Emperor", which can make the foreign audience make the same reaction as the domestic audience and is in line with the concept of functional equivalence. 
Example 2: 我所犯之罪乃十恶之九。

My crime was the worst of all.

In this line, "十恶之九" does not emphasize the quantity, but the unforgivable crime of Zhang Xiaojing. Therefore, it's almost impossible for him to leave death row. Rendering the phrase as "the worst of all" can directly and clearly convey the original sentence meaning so that the audience can react quickly, which also contributes to the development of the subsequent plot. Under functional equivalence, if meaning and culture cannot be taken into consideration at the same time, the translator can only abandon formal equivalence and change the form of the original text to achieve the purpose of reproducing the connotation and culture of the original text.

Example 3: 他私放钱贷，超过了长安能容忍的数量。

He was an illegal loan shark. His action exceeded the tolerance of our laws.

In this example, "私放钱贷" means"lend money to others illegally". The use of "loan shark" an equivalent word in English, can achieve semantic and cultural equivalence, and enable the target audience to respond quickly within the limited time to read the subtitles and achieve a correct understanding of the original text. In addition, in order to ensure smooth writing and rigorous logic, the word "数量 (quantity) " was also replaced by "action" accordingly.

\section{ii. Syntactical equivalence}

Chinese and English belong to different language families and have different language characteristics. Chinese is a paratactic language, frequently relying on covert coherence and context, without strict grammars, while English is a hypotaxis language with strict grammatical structure. Nida pointed out that "In dynamic equivalence translation, the translator focuses on the meaning and spirit of the original text without adhering to the language structure of the original text, that is, without adhering to formal correspondence" (Tan Zaixi, 1989). This requires translators to fully grasp the linguistic features of the Chinese and English languages during the translation process.

Example 4: 熙攘繁盛, 光耀万年。

All are thriving and glory shines upon it.

Chinese prefers four-character patterns and pay attention to phonological harmony. When describing and rendering big scenes, repetition and exaggeration are always deployed; while English emphasizes briefness and correct grammar. In this example, the original text is two parallel four-character patterns, concise and well-proportioned, which is fairly expressive along with a magnificent picture. In order to conform to the English audience's reading habits, the translator using thriving to cope with repetition "熙攘(bustling)"and "繁盛(glorious)" and omit the exaggeration"万年(ten thousand years)". In addition, using the conjunction "and" to connect two simple sentences not only conveys the meaning of the line but also retains a sense of rhythm.

Example 5: 我姓李, 但我的李却不是唐李, 乃前朝隋李。

I carry the family name of $L i$, but it's not the same as the royal family. It was from the noble of the previous dynasty.

In this example, paraphrasing has been employed to translate "唐李( royal surname of Tang Dynasty" and "前朝隋李 (royal surname of Sui, a previous Dynasty of Tang)", but directly used several declarative sentences to explain the meaning of this sentence. Taking the time and space limitations of subtitle translation into account, it is not recommended to use annotation to cope with cultural connotations, which will increase audiences' reading time and spoil the audiences' viewing experience, while paraphrasing can smoothly promote the development of the plot.

Example 6: 长安城一百零八坊，每三百步设一望楼。望楼上武侯皆为朔方节度使所派㛎兵。

There are 108 streets in Chang'an. There is a watchtower at every 300 steps. The commandants on top are sent by the Commissioner of the north.

In this example, the translator fully considers the characteristics of subtitle translation. The first sentence means "there are 108 streets in Chang'an, where there is a watchtower every 300 steps." Given the time and space limitation of subtitle translation, "the number of subtitle words should correspond to the time that image and sound stay" (Li Yanwei, 2021), therefore a long, complex sentence is not appropriate, so this line was translated into two separate sentences to convey the semantic meaning while avoid reading obstacles to the audience. 
iii. Stylistic equivalence

Functional equivalence gives priority to meaning, followed by style. But the style is also significant. In subtitle translation, the realization of stylistic equivalence can reflect the vivid personalities of various characters.

Example 7: 大唐还没到是个公子哥就可以无视唐律的时候。

The Tang Dynasty hasn't fallen to a point where a boy can call the shot.

In this example, Zhang Xiaojing thinks Li Bi is a "公子哥(son of a rich family)", because Li is young but has the power to let Zhang out of the death row, and wants to save Chang'an. Actually, Li Bi is a handsome young man, rather than a boy. The translator uses "boy" to describe him can reflect that Zhang's bohemian and is scornful of Li Bi's confidence. This kind of treatment vividly shows Zhang Xiaojing's personality and reflects the stylistic equivalence.

Example 8: 今日你在长安何处, 我随时可知。想逃是不可能的。

Wherever you are in the city, I will know. An escape is impossible.

$\mathrm{Li} \mathrm{Bi}$ is thoughtful, confident, and ambitious. His speaking is always short and decisive, without any nonsense. In order to achieve stylistic equivalence, the translation did not translate "何处 (where) " and "随时(at any time)", but directly used "wherever" to show Li Bi's self-confidence and the briefness of his words, which is also a kind of stylistic equivalence.

Example 9: 我眼高于顶, 时刻挑剔。如果你事情办得不妥, 我随时请你回死牢。

I ask very highly of you and demand a lot. If you failed, you will be back on death row in no time.

In the second sentence of this line, the translator changed the voice and subject. As a powerful and well-known person, Li Bi has the power to determine Zhang's life, and naturally, he needn't be polite to him. Therefore, although he is literally courteous and thoughtful, the Chinese audience can easily understand the impoliteness behind it. The translator changes the subject from active to passive, which can better reflect that Li Bi believes he can dominate Zhang Xiaojing's destiny, and achieve stylistic equivalence.

\section{Conclusion}

This paper mainly studies subtitle translation methods of ancient costume drama with cultural heritage. Under the guidance of functional equivalence theory and considering the characteristics of subtitle translation, the author has found: when translating subtitles with strong cultural heritage, attention should be paid to lexical, syntactical, and stylistic equivalence and pursue the correct expression of syntactic meaning and cultural elements. In addition, the personalities of characters and style of a drama should also be taken into consideration. In the translating process, cultural equivalents can be used. In addition, translators should fully understand and reflect the characters' personalities and style of a drama or movie. Translation methods such as free translation, omission, and paraphrasing can be used, while literal translation is unnecessary.

This research can not only provide guidance for subtitle translation of Chinese costume drama but also promote Chinese culture abroad. Due to limited materials, the number of examples is not enough to cover all translation problems of subtitle translation of costume drama. Therefore, maybe relative future research can try to cover different problems as much as possible.

Funding: This research was funded by the Wuhan University of Technology, grant number W2019135

Conflicts of Interest: The authors declare no conflict of interest 


\section{References}

[1] Zhengqi M. (2012). On the Translation Methods of Subtitle Translation. Modern Communication Journal of the Communication University of China,34(03),64-68.

[2] Heqing L. (2005). Norms in Subtitle Translation. Chinese Science \& Technology Translators Journal, (02),44-46.

[3] Xi C. (2014). On Three working modes of film and television subtitle translation in China. Theory and Practice of Contemporary Education, 6(08), 159-161.

[4] Lei H (2012). Current Situation and Development of Subtitle Translation. Movie Literature, (03), 152-153.

[5] Eugene, N. (1964). Toward a Science of Translating. Leiden: E.J. Brill.

[6] Eugene, N. (1982). Language, Culture, and Translating. Shanghai Foreign Language Education Press.

[7] Chunbai Z. (1998). On Subtitle Translation. Chinese Translators Journal, (02), 4.

[8] Chunxiang C. (2012). A Study on Cultural Correspondence strategies in Subtitling Translation with Principles of Equivalence [Master's thesis, Southwest University]. China National Knowledge Infrastructure. https://kreader.cnki.net/Kreader/CatalogViewPage.aspx?dbCode $=c d m d \& f i l e n a m e=2010121272$. nh\&tablename $=$ CMFD2010\&compose $=\& f$ irst=18uid=WEEvREcwSIJHSIdSdmVqMDh6a1hCNGVxRnFERFg1NTRmUDRBNUh2QOIDMD0=\$9A4hF YAuvQ5obgVAqNKPCYcEjKensW4IQ MovwHtwkF4VYPoHbKxJw!!

[9] Zaixi T (1989). Nida and His Translation Theory. Journal of Foreign Language, (05), 9.

[10] Yanwei L (2021). On Subtitle Translation of the Marvelous Mrs. Maisel Season 2 from the Perspective of Functional Equivalence. Overseas English, (14), 38-39+42. 